\title{
Rock scour in Australia: some latest Queensland experiences
}

\author{
E. Bollaert \\ AquaVision engineering, Ecublens, Switzerland \\ E. Lesleighter \\ Lesleighter Consulting, Sydney, Australia
}

S. McComber, P. Bozorgmehr, L. Fahey \& D. Scriven

Sunwater, Queensland, Australia

\begin{abstract}
From 2010, a succession of floods in eastern Australia, and particularly in Queensland, brought about spillway operation at high head dams with return periods in the region of Annual Exceedance Probabilities (AEP) of up to 1 in 2,000 years. As such, a number of spillways experienced extensive scour of rock downstream - including Boondooma Dam and Paradise Dam - the subject of the present paper. For both dams, part of the scour assessment process has been to utilise a large-scale physical model to obtain transient data which, together with the detailed geologic assessment, have been incorporated into the numerical scour modelling procedures developed by Dr Erik Bollaert. This paper will first of all describe the features of the 2011 and 2013 flood events at both dams, as well as the resulting rock scour and damage on both spillways and the geology of the rock area below. The paper will then go on to describe the computational scour modelling procedures of calibration and application, used in conjunction with a large-scale physical model of both dam and spillway, demonstrating a "system" approach to spillway scour analysis for plunge pools and similar situations with energy dissipation on natural materials.
\end{abstract}

\section{INTRODUCTION}

Since 2010 a succession of floods in eastern Australia, and particularly in Queensland, brought about spillway operation with return periods in the region of Annual Exceedance Probabilities (AEP) of 1 in 2,000 or more. Rock scour at Wivenhoe Dam (near Brisbane) has already been discussed in a number of publications (Lesleighter et al., 2012; Lesleighter et al., 2013; Bollaert \& Lesleighter, 2014; Bollaert et al., 2014).

The present paper discusses the main scour issues and related studies ongoing at Paradise Dam and Boondooma Dam, both operated by Sunwater Ltd.

\section{PARADISE DAM}

\subsection{General}

Paradise Dam was constructed on the Burnett River, Queensland, some ten years ago. It is a classical RCC dam with a $315 \mathrm{~m}$ long stepped primary spillway with an ogee crest level of EL $67.6 \mathrm{~m}$ and provision for flood levels to well in excess of EL $85 \mathrm{~m}$.

The crest is constructed in conventional reinforced concrete and the downstream stepped face is capped with reinforced concrete anchored into $620 \mathrm{~mm}$ tall RCC steps. At the base of the steps, spillway flows meet a horizontal apron of $20 \mathrm{~m}$ in length with a ver- tical end sill $1 \mathrm{~m}$ in height. At the left end of the spillway the original apron was at a level of EL37.6 $\mathrm{m}$, and at the right end the apron was at only EL30.9 $\mathrm{m}$. This means that spillway flows are transferred downstream at different levels, creating asymmetric flow conditions in the unlined stilling basin.

Figure 1 is a photograph of the dam and spillway, taken after dam construction and prior to severe flooding at the site. Figure 2 shows a sectional view of the primary spillway and apron.

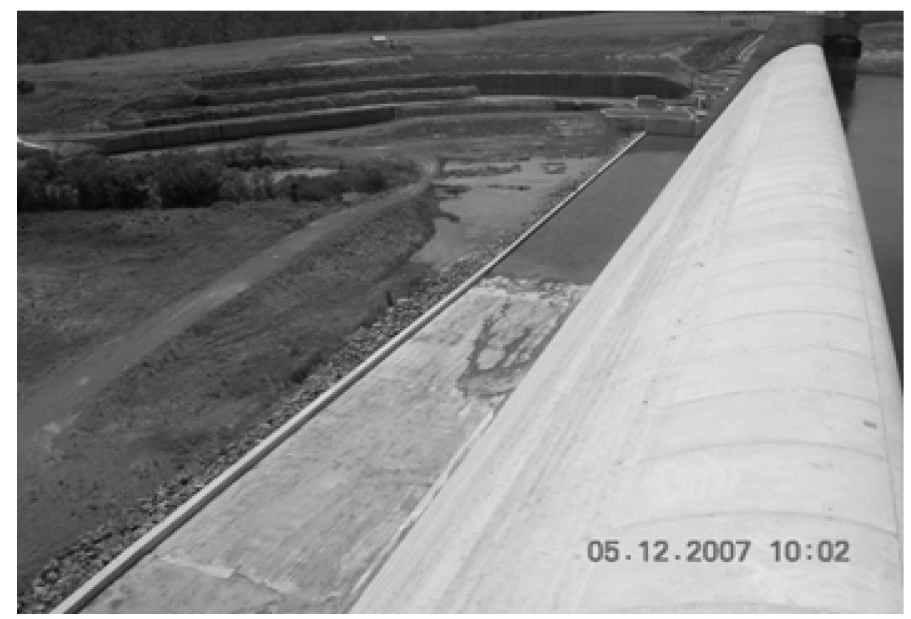

Figure 1. View of primary spillway of Paradise Dam 


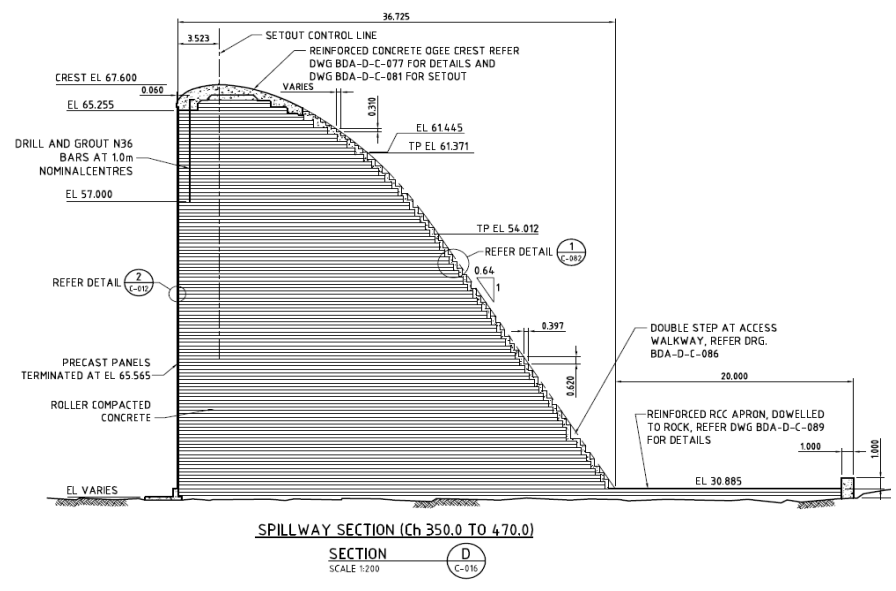

Figure 2. Sectional view of primary spillway of Paradise Dam

\subsection{Recent flood events}

Apart from relatively minor flooding, a flood with a peak discharge with an Annual Exceedance Probability (AEP) of 1 in 30 occurred in 2010-2011. The primary spillway was overtopped by $6 \mathrm{~m}$ on the $29^{\text {th }}$ December 2010. The reservoir level peaking at EL $73.6 \mathrm{~m}$ remained above the crest level for more than three weeks. The peak discharge was equivalent to approximately $9,600 \mathrm{~m}^{3} / \mathrm{s}$, or a unit discharge, $\mathrm{q}$, of $30.48 \mathrm{~m}^{2} / \mathrm{s}$.

This flood caused a certain amount of "readjustment" of the loose rock and alluvium and some damage to the stilling basin apron due to "ball milling" effects from rock in motion.

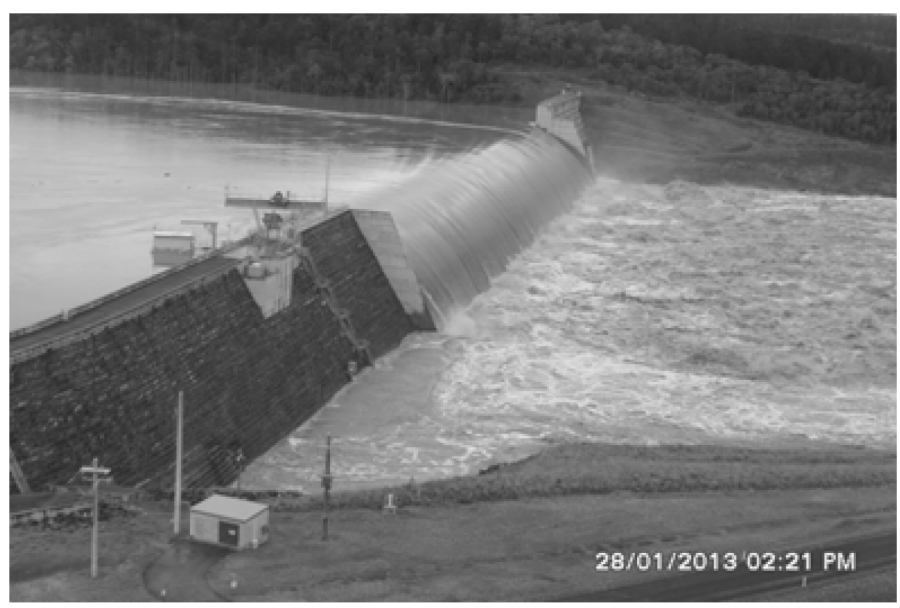

Figure 3. 2013 flood at Paradise Dam primary spillway

An appreciably larger flood (AEP of 1 in 180) occurred in January 2013 (Fig. 3). The peak reservoir level was EL $76.2 \mathrm{~m}, 8.6 \mathrm{~m}$ above the crest, and the corresponding discharge was $17,090 \mathrm{~m}^{3} / \mathrm{s}$; a unit discharge of $54.3 \mathrm{~m}^{2} / \mathrm{s}$. The Paradise outflow hydrograph is shown in Fig. 4.

Table 1 presents the AEP discharges up to the AEP 1 in 10,000. The 2013 flood corresponds to an AEP of about 1 in 180.
Table 1. Paradise Dam AEP Discharges

\begin{tabular}{|c|c|}
\hline AEP ( 1 in year $)$ & Discharge $\left(\mathrm{m}^{3} / \mathrm{s}\right)$ \\
\hline 50 & 12,840 \\
\hline 100 & 15,410 \\
\hline 200 & 17,490 \\
\hline 500 & 20,820 \\
\hline 700 & 22,330 \\
\hline 1,000 & 24,440 \\
\hline 2,000 & 28,180 \\
\hline 3,000 & 31,950 \\
\hline 10,000 & 48,740 \\
\hline
\end{tabular}

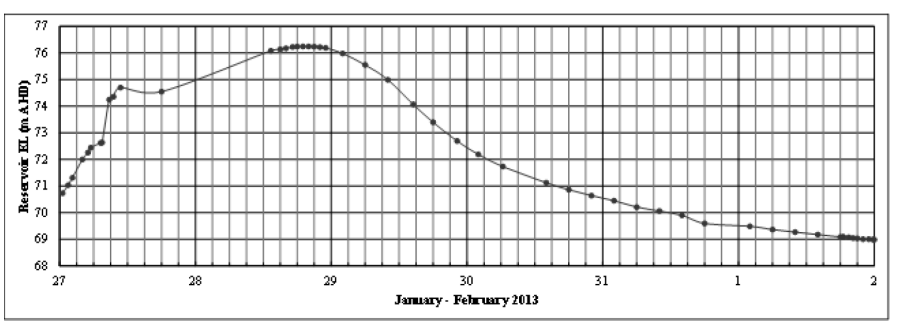

Figure 4. 2013 flood hydrograph at Paradise Dam

In contrast with the 2010-2011 flood, the 2013 flood caused extensive and deep scour downstream of the apron, as well as removal of the $1 \mathrm{~m}$ high end sill of the concrete apron (Figs. 5-6).

The scour hole attained a depth of almost $15 \mathrm{~m}$ along the left hand side of the spillway, where the apron elevation was significantly higher than in the center and right hand side. The corresponding scour formation along the right hand side only reached about 3-4 m depth. Both scour holes significantly regressed underneath the concrete apron towards the dam foundations.

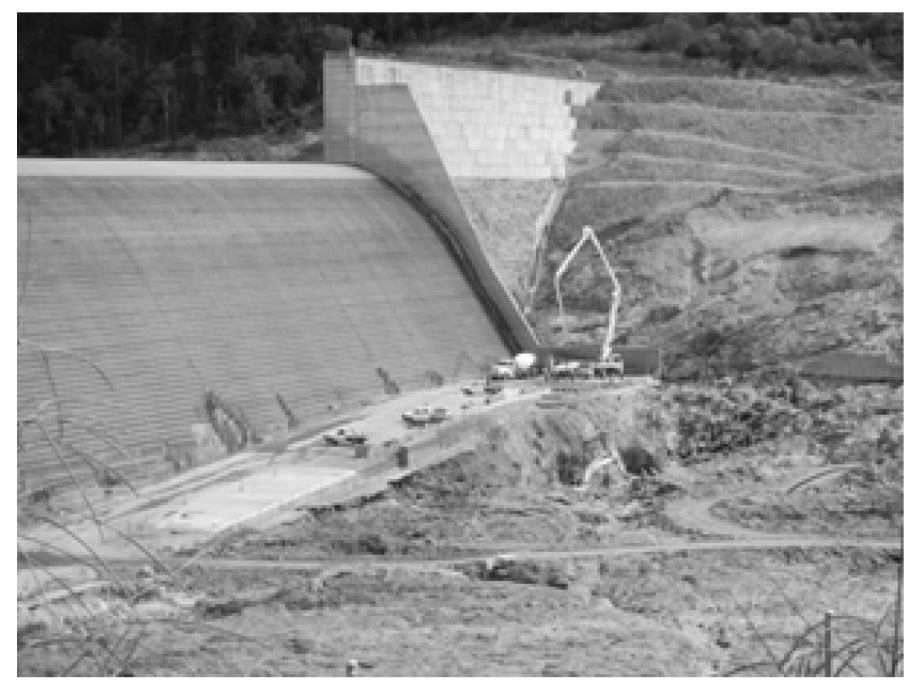

Figure 5. Rock scour at Paradise Dam following 2013 flood 


\subsection{Geology}

The scour from the 2013 flood (Figs. 5-6) demonstrated a geologic condition that provided scant resistance to the energy dissipated during the four to five day 2013 flood. The dam is generally founded on meta-sediments known as the "Goodnight Beds" except on the right side near the outlet works, where it is founded on basalt known as Barambah Basalt. Following the flood of 2013 and subsequent scour, further geotechnical investigations were undertaken. Features of particular note are faults, termed the "Paradise Fault" and the apron faults.

The Paradise fault, located downstream of the dissipater slab is a zone of Goodnight Beds which has been subjected to intense structural deformity. The zone is characterized by a series of closely spaced shears, dykes and faults. These features are steeply dipping.

The apron faults are a series of major thrust faults which meander between outcropping downstream of the dissipater slab or concealment under the slab. These faults dip moderately underneath the dissipater slab.

The deep scour that occurred in the 2013 flood, relatively close to the apron, including the removal of the vertical end sill, led to a series of investigations and analyses related to dam stability and the part that the geologic conditions played in the dam's integrity. It was necessary to augment the geologic knowledge of the site by extensive site investigations and mapping.

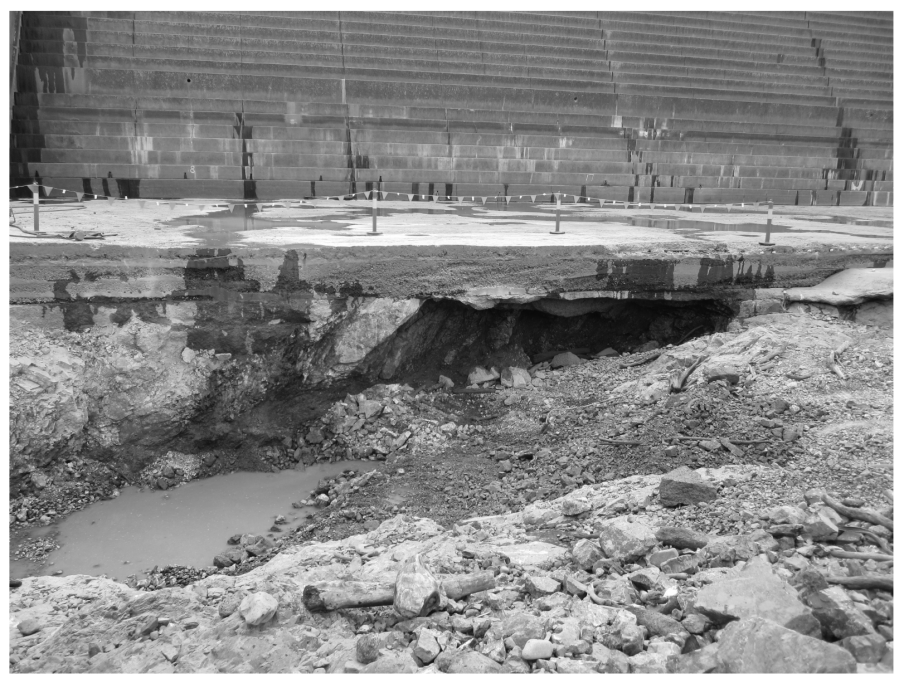

Figure 6. Apron undermining following 2013 flood

The safety evaluations included not only the depth of scour that had occurred - up to $15 \mathrm{~m}$ below apron level in one location - and the geologic investigations, but also investigation of the integrity of the concrete in the spillway apron. At an early stage following the 2013 flood, concrete works were implemented immediately downstream of the apron and included a capping slab on the apron itself. These measures aimed to be an interim repair while the more detailed studies were being carried out.

As it was clear that future floods may lead to more extensive scour of the apron and rock downstream of the apron, the dam owner defined and initiated additional studies of the geology and evaluations of the stability of the dam as well as the program of hydraulic modelling and numerical scour modelling which are the subject of the present paper.

\section{BOONDOOMA DAM}

\subsection{General}

Boondooma Dam is located on the Boyne River, approximately $20 \mathrm{~km}$ northwest of Proston. Construction of the dam was completed in August 1983. The spillway consists of a $2 \mathrm{~m}$ high, $115 \mathrm{~m}$ wide concrete crest and an unlined tapered discharge chute through a ridge of volcanic rock. A reinforced concrete Erosion Control Structure (ECS) was constructed $133 \mathrm{~m}$ downstream of the spillway crest. The purposes of the ECS were to ensure flows would spread evenly across the weaker rock zones and to create a nonscourable barrier. The drop of $7 \mathrm{~m}$, downstream of the ECS, was to dissipate energy.

The primary purpose of the dam is to supply water to Stanwell Corporation's Tarong Power Station. In addition, the dam supplies small amounts to irrigators along the Boyne River.

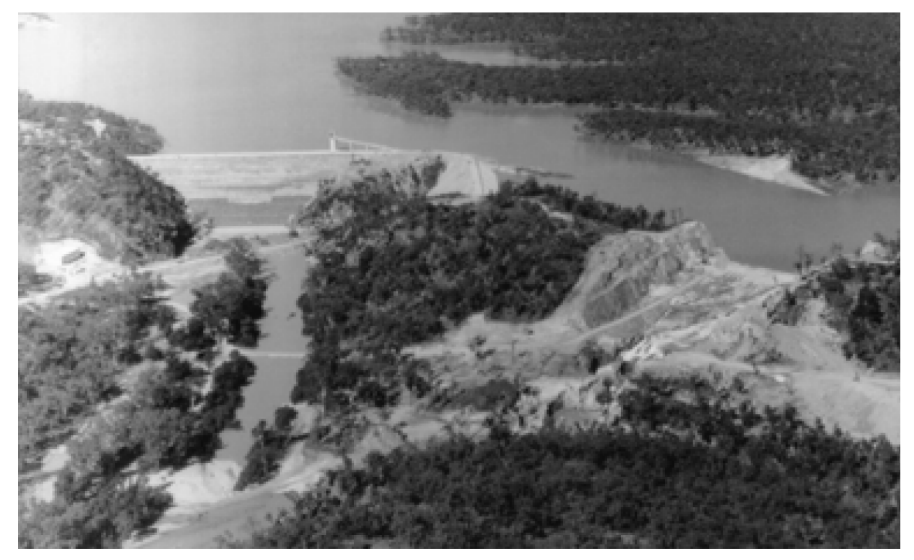

Figure 7. Aerial view of Boondooma Dam (left) and of unlined discharge chute (right)

\subsection{Recent flood events}

Spilling commenced on 5 December 2010 and continued until the end of February 2011 (Fig. 8). The total inflow volume was recorded as $1,080,000 \mathrm{ML}$, which is 5.3 times the storage volume of the dam. There were four distinct flood peaks during this flood event. The highest peak occurred on 11 January 2011 at $3.7 \mathrm{~m}$ over the spillway. The peak discharge was approx. $1,600 \mathrm{~m}^{3} / \mathrm{s}$ (140,000 ML/day).

The AEP of this event was estimated to be 1:30 years. This represents the highest recorded flood for 
the dam to-date. The spillway outflow caused major scour damage to the spillway chute. Post flood inspection found damage to the chute including:

- Large scour holes in the spillway chute located between the spillway crest and the ECS. The deepest hole was located on the right hand side just upstream of the ECS (Fig. 9). There were also several other scour holes up to $1.5 \mathrm{~m}$ in depth over the chute.

- Severe scour to the chute downstream (Fig. 10)

Following the 2010/11 flood event, emergency repair works were undertaken to rectify the damage between the ECS and the spillway crest. Concrete was used to fill the scour holes, and a line of defensive anchors was installed immediately upstream of the ECS.

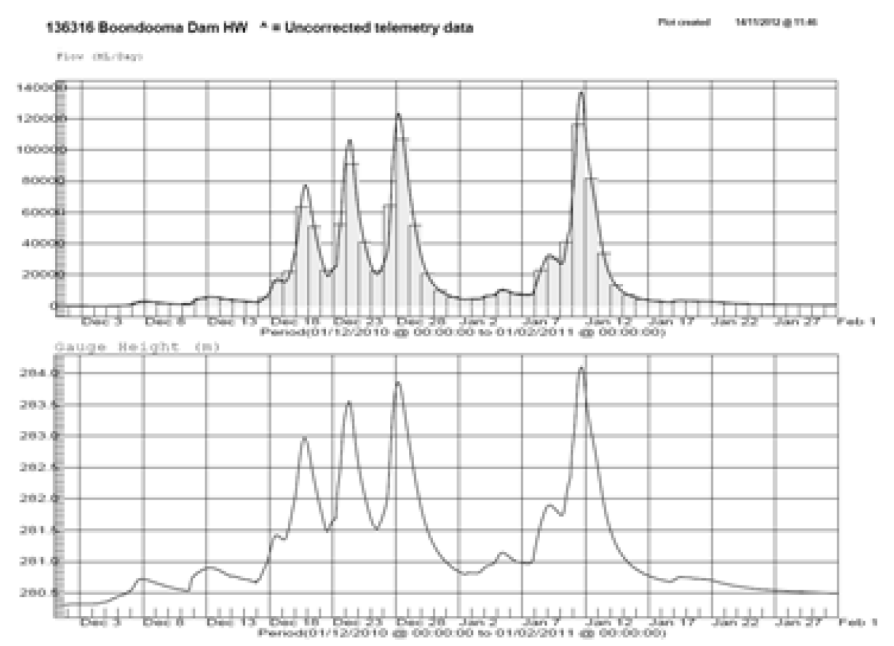

Figure 8. 2010-2011 flood reservoir levels and outflows at Boondooma Dam

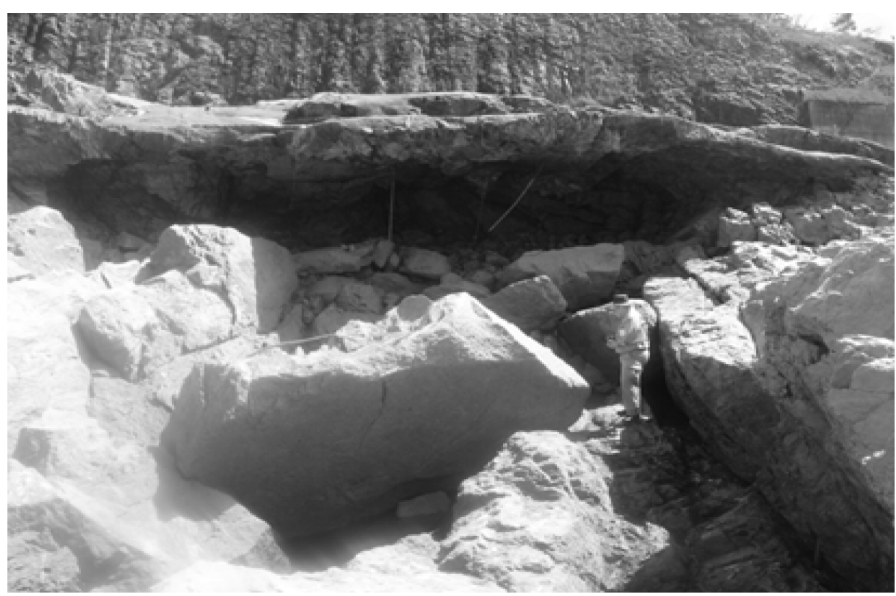

Figure 9. Large scour hole in spillway following 2010-2011 flood event at Boondooma Dam

During the Tropical Cyclone Oswald weather event on the Australia Day long weekend in 2013, Boondooma Dam commenced spilling again. The dam spilled from 27 January and continued until 9 February 2013 (Figs. 11-12).

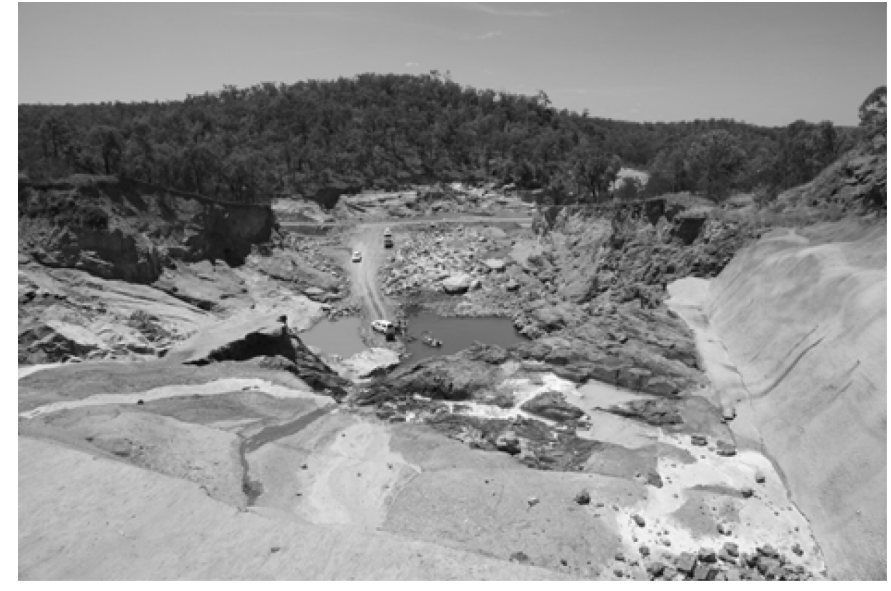

Figure 10. Large scour hole in downstream part of spillway following 2010-2011 flood event at Boondooma Dam

The AEP of this event was estimated to be 1:200 years. The peak discharge was equal to $3,500 \mathrm{~m}^{3} / \mathrm{s}$. This is the flood of record for the dam. The damage was confined to the spillway, with further scour occurring between the spillway crest and the ECS. Further scour downstream of the ECS also occurred.

Following the 2013 flood event, emergency repair works were undertaken by filling the scour holes with concrete.

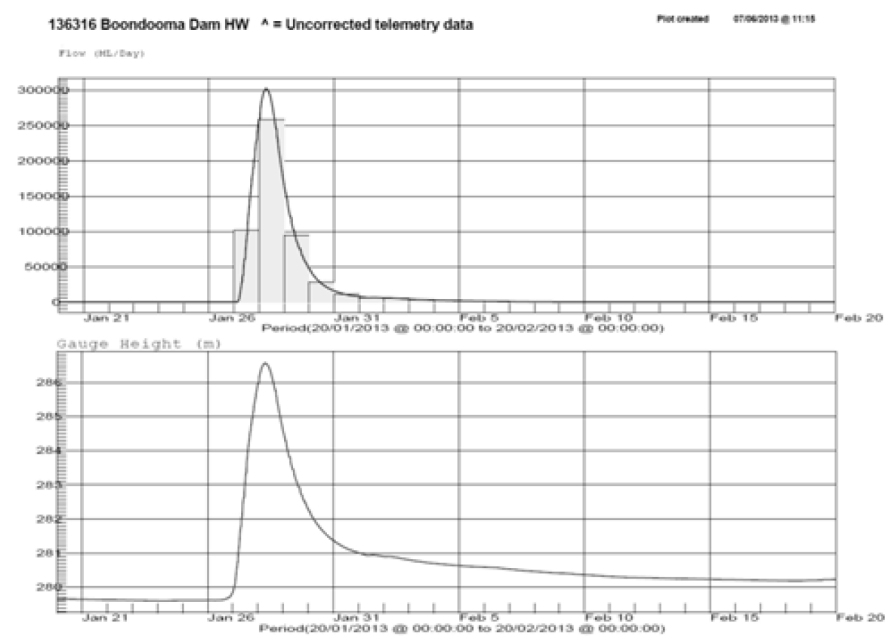

Figure 10. 2013 flood reservoir levels and outflows at Boondooma Dam

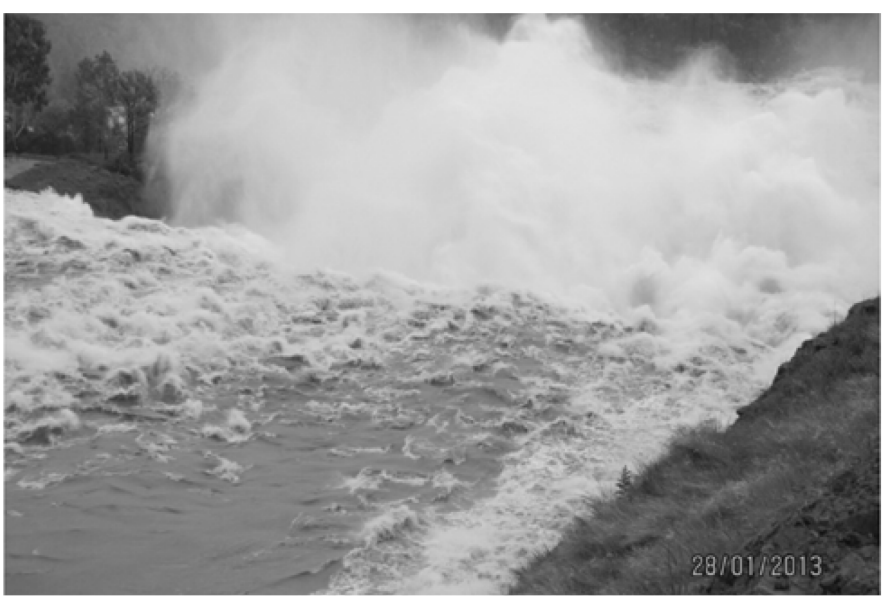

Figure 11. 2013 flood event at Boondooma Dam 


\subsection{Geology}

The lithology is quite complex and mainly consists of granite and microgranite downstream of the ECS, where a large scour hole developed during the 2011-2013 flood events. Main sub-vertical dykes of volcanic material traverse the granite.

Upstream of the ECS, the lithology is composed of different volcanics together with main subvertical dykes oriented from up-to downstream and allowing the spillway chute to easily erode and break up into large pieces. Lithologies that can be observed are tuff, ignimbrite, rhyodacite, volcanic breccia, and andesite, dolerite and rhyolite dykes.

UCS strengths vary between 7 and $136 \mathrm{MPa}$, and rock blocks may be very flat, depending on the lithology. Most of the material has a high initial degree of fracturing and contains numerous fissures.

\section{SCOUR MODELLING}

\subsection{Procedure}

A new scour modelling procedure has been adopted for both dams, based on hybrid modelling. Hybrid modelling combines a soundly scaled physical laboratory model with a physics based 2D numerical model, incorporating both hydrodynamics and geomechanics in a detailed manner.

The flow turbulence parameters recorded on the physical model in terms of dynamic pressures, flow velocities and water levels are thereby used as direct input to the numerical model, which allows the latter to model in detail the interaction between the hydrodynamic action of the water and the mechanical resistance of the rock mass against scour.

As a first step, sound calibration of the numerical model is performed based on historic flood events tested and recorded on the physical model. Next, future flood events with different return periods are simulated numerically. This allows determining the potential for future scour damage at each part of the unlined stilling basin, especially in terms of risk for scour regression towards the dam toe and undermining of the apron.

Once the scour potential is defined, appropriate scour countermeasures are developed and tested firstly on the physical model. Again, the flow turbulence parameters recorded are used as input to the numerical model, to check for any further scour potential.

The whole process of going back and forth between the physical and the numerical model is repeated until appropriate countermeasures are obtained.

\subsection{Paradise Dam hybrid modelling}

A physical model was built and tested by the Manly Hydraulics Laboratory (MHL), Sydney NSW for detailed scour studies. The model was built to a scale of 1:70, with the ability to test for discharges up to the AEP 1 in 10,000 years. It was set up to investigate the spillway as-built condition, the post-2011 flood condition, the post-2013 flood condition including interim works, and studies of the secondary spillway overflow of the right abutment of the dam.

Figure 12 provides a view of a portion of the model with some of the flush-diaphragm transducers. Figure 13 shows the model operating at a midrange discharge. Model instrumentation included more than 60 pressure transducers, a large number of piezometers, an Acoustic Doppler Velocimeter (ADV), with electromagnetic flow metering up to model discharges of 1,200 L/s. Figure 14 illustrates the pressure transducer coverage on several lines.

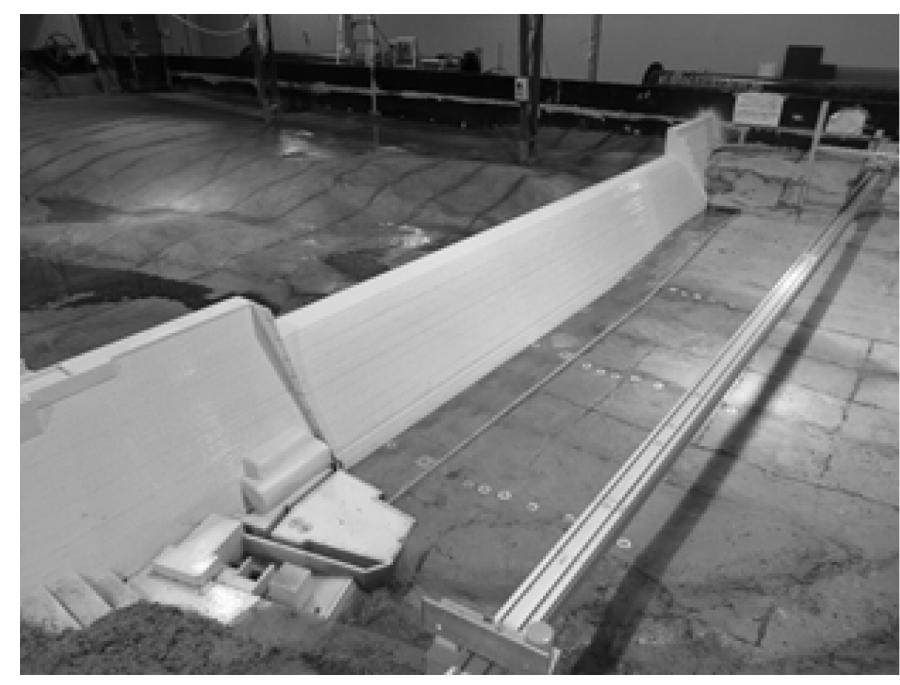

Figure 12. 1:70 scale physical model of Paradise Dam at MHL

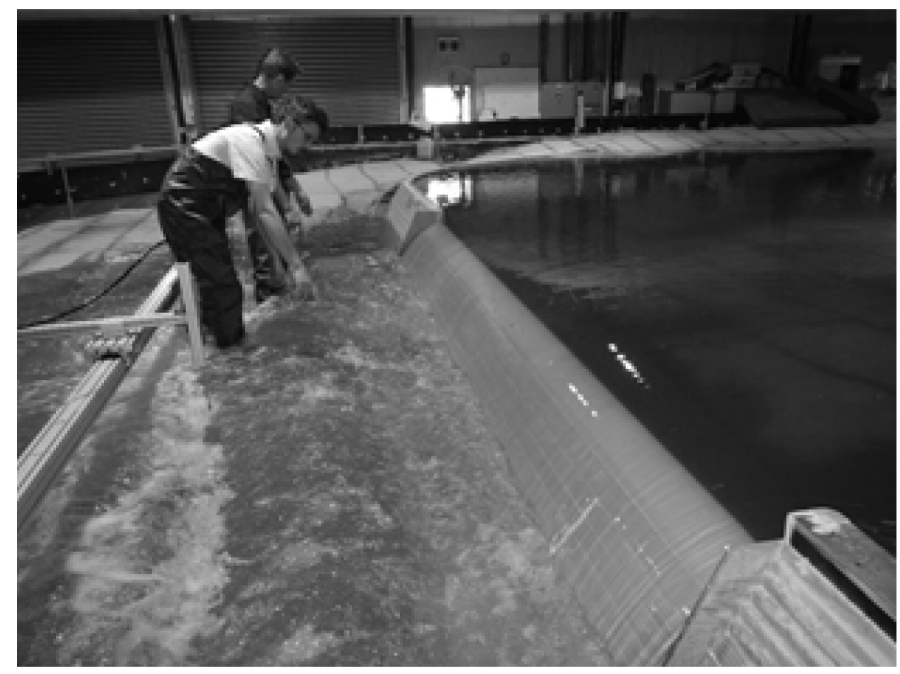

Figure 13. AEP500 flood at MHL physical model

The sensors used were Keller Series 25 flush diaphragm temperature-compensated vented-gauge transmitters factory-adjusted to provide a singleended high level linear output from 30 to +200 mbar. 
Velocity measurements were made using a SonTek $10-\mathrm{MHz}$ ADV. Velocities at each measurement location (subject to the water depth) were recorded at four or five heights for each flow test in the $\mathrm{x}, \mathrm{y}, \mathrm{z}$ directions. All ADV velocity measurements were recorded at a sampling rate of $20 \mathrm{~Hz}$ for a 60 -second period. The transient pressures at 58 locations in the spillway apron and downstream were measured at a sampling rate of $400 \mathrm{~Hz}$ for a period of $150 \mathrm{~s}$ $(60,000$ values $)$.

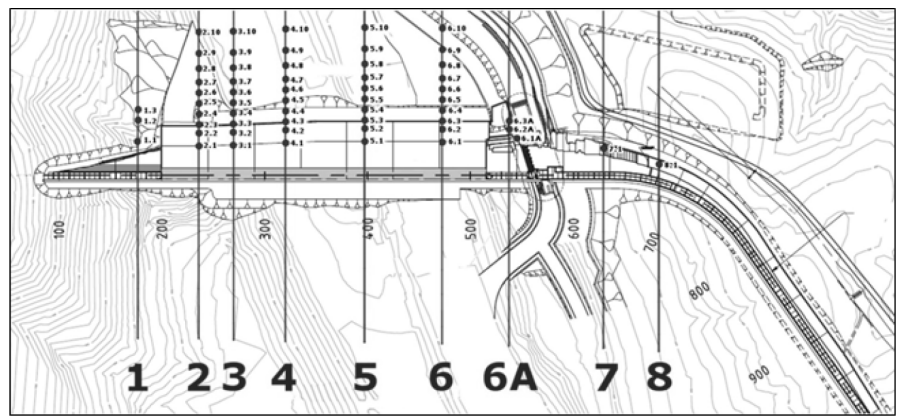

Figure 14. Plan view of dam and lines of pressure recordings

The Comprehensive Scour Model comprises three methods that describe failure of jointed rock. The Comprehensive Fracture Mechanics (CFM) method determines the ultimate scour depth by expressing instantaneous or time-dependent joint propagation due to water pressures inside the joint. The Dynamic Impulsion (DI) method describes the ejection of rock blocks from their mass due to sudden uplift pressures. The Quasi-Steady Impulsion Model (QSI) describes peeling off of rock blocks from their mass by quasi-steady wall jet flows. The structure of the Comprehensive Scour Model consists of three modules: the falling jet, the plunge pool and the rock mass. The latter module implements the aforementioned failure criteria. More details on equations which describe the hydrodynamics can be found in Bollaert (2004).

The 'falling jet' module describes how the hydraulic and geometric characteristics of the jet are transformed from dam issuance down to the tailwater pool. The 'plunge pool' module describes the characteristics of the jet when traversing the pool into which the jet impinges and defines the water pressures at the water-rock interface. In the Paradise situation, the overflow jet impacts the tailwater and spreads to then be deflected by the apron into the tailwater on the way to impacting the rock, generating in this way a sort of semi-submerged hydraulic jump turbulence. Finally, the 'rock mass' module contains the aforementioned rock break-up methods. The main hydrodynamic parameters used by the CSM 'rock mass' module are the bottom flow velocities and: the fluctuating and maximum dynamic pressures coefficient, the characteristic of the pressure cycles, and a maximum dynamic impulsion coefficient. In here, these have been recorded firstly on a physical model for different discharge scenarios, to be used next as input by the CSM. Full details of the numerical rock break-up modules are outside the scope of this paper and for a comprehensive discussion of the components of the methodology and their direct relevance to the dynamics of rock scour is described by Bollaert et al. (2015) (ICSE Perth).

The detailed analyses that have applied the CSM procedures passed through two stages of calibration using the actual flood hydrograph in histogram format, and use of the calibrated model to estimate scour flood various discharge scenarios. The calibration for the most part used the actual hydrographs of the 2013 flood. The calibration analyses for one of the profiles downstream of the spillway, Line 2 (see Figure 14), are shown in Figure 15.

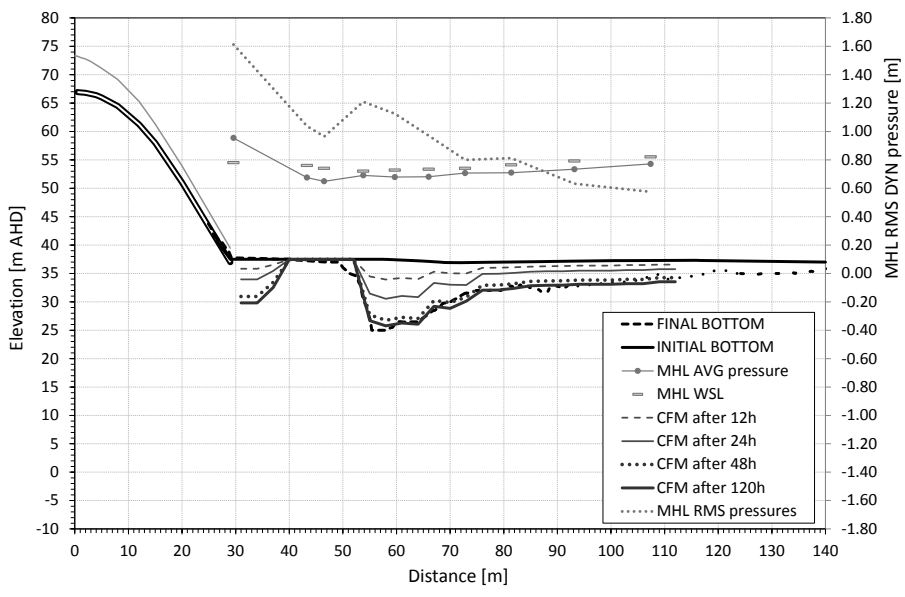

Figure 15. CSM calibration for 2013 flood at line 2

In the 2013 flood the rock scour was extensive. The figure shows the estimate of progressive scour with time for 6 to 120 hours exposure. These may be compared to the black dashed profile which is the surveyed profile following the 2013 flood.

On the basis of a successful calibration, the CSM procedure was in a position to proceed to analysis of future scour. For those procedures it was necessary to determine a long-term series of flood discharges that could be applied to determine on a time or year basis the expected scour that could occur downstream of the primary spillway.

Using the selected discharge scenarios and the dynamic pressures and flow velocities as measured on the physical model, the CSM model was set up also to investigate possible works if they were determined to be required.

Figure 16 is an example of the estimated potential scour downstream of the existing apron for a range of discharges devised to represent a scenario of six floods with discharges ranging from an AEP of 100 to an AEP of 1 in 10,000. The Comprehensive Fracture Mechanics module is deemed to represent the possible scour progress for the selected hypothetical range of floods and discharges. It has to be noted that the scour profiles "under" the apron (distance 
$30 \mathrm{~m}$ to $50 \mathrm{~m}$ ) apply to the possible scour in the event that the apron was actually removed.

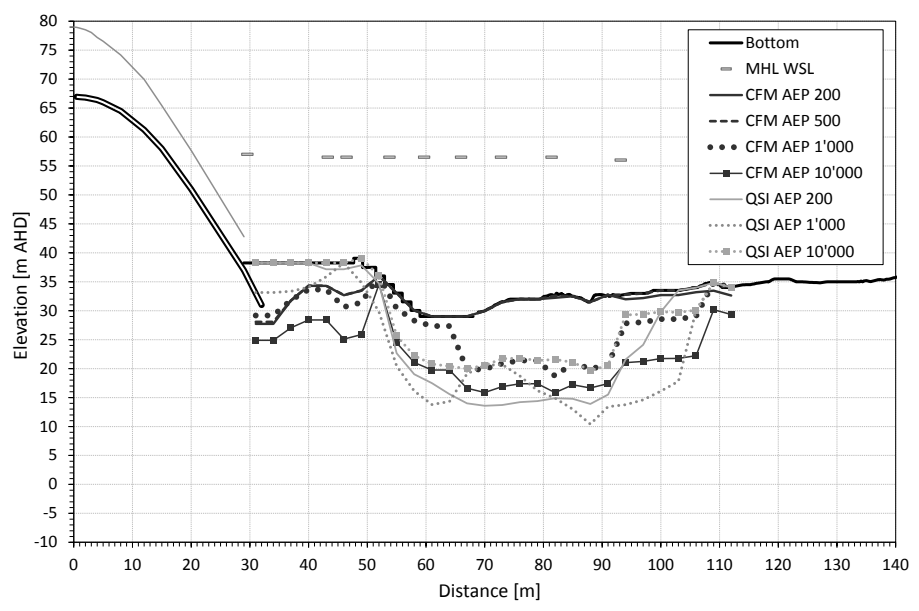

Figure 16. Computed scour potential at Paradise Dam for different AEP flood events

\subsection{Boondooma Dam hybrid modelling}

In 2014, SunWater initiated the preliminary design phase of its preferred repair option (McComber \& Bozorgmehr, 2015). As part of the preliminary design, further physical modelling was required to provide input into the Comprehensive Scour Model (CSM) (Bollaert, 2002), which is a key tool to determine the design life of the repair options under consideration and to help estimate how the spillway may perform in future flood events.

The post 2010/11 flood profile was used as the main input to calibrate the CSM. Discharges included the 1:5, 1:20, 1:30, 1:50, 1:100 and 1:200 AEPs.

The post 2013 profile data would be used by the CSM to predict the scour profile for future floods. The CSM would need a range of flow discharges that are likely to occur in the future and are capable of causing damage in the unlined area of the upper and lower chute. Six scenarios were chosen that cover a wide range of flow discharges from AEP30 to AEP10,000.

Observation of larger flows indicated that while these flows are capable of creating bigger scour holes; their location would be further from the ECS as the jets would drop into the body of the plunge pool area. The larger distance between the jets' foot print and the ECS means that flows larger than 1:10,000 are less likely to threaten the ECS structure. The areas affected by those jets (generated in flow discharges larger than Q10, 000) may not need the same level of protection that the ECS and upper chute would require.

Model topography

It was necessary to reproduce the spillway chute topography in detail to ensure that the flow characteristics exiting the ECS replicated those witnessed in the prototype. The dropping into the plunge pool, the energy conditions and the effect of roughness on the boundary layer had to be accurate in order to create the turbulence witnessed in the flood events.

As the original model spillway chute surface was made of smooth Perspex, modifications were required in order to replicate the required flood characteristics. These modifications sought to replicate the very rough surface of rock on both the upper and lower chutes.

After the last two major flood events of 2011 and 2013 , laser survey of the spillway site was undertaken. The survey information closely matched the observations and photos taken after the flood event. The results of the surveys showed that about $65,000 \mathrm{~m}^{3}$ materials was dislodged and carried away from the site in 2013 event.

The modifications for the upper spillway chute were achieved through the use of a Computer $\mathrm{Nu}$ merical Control (CNC) machining process. The surface profiles were obtained from laser surveys undertaken after both flood events. This survey data provided the input for the CNC machining. The post 2010/11 survey was undertaken following emergency repairs, and the post 2013 survey pre-repairs. A comparison between the two sets of survey data showed no major difference between the profiles; therefore, the post 2013 profile was adopted for the upper chute topography.

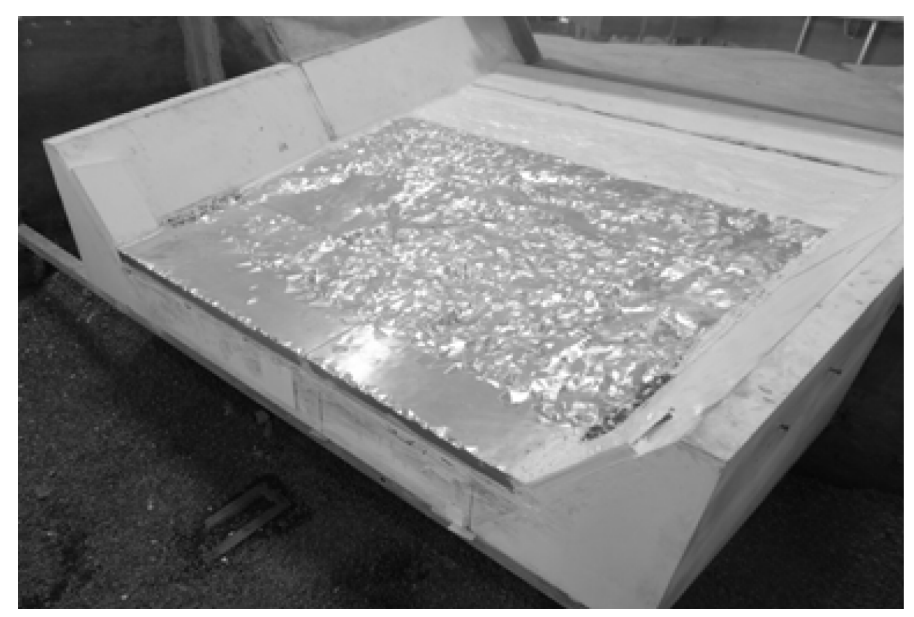

Figure 17. Upper chute arrangement with CNC milled aluminium

This method provided an accurate surface profile of the spillway upper chute floor by milling of aluminium billets to a desired accuracy. The choice of aluminium as base material was due to its advantages as listed below:

- It is a strong material that can handle all hydraulic forces with ease

- Unlike most metals, it is light enough to work with

- It is an easy material for laser cutting

- Its waterproofing quality. There was no leakage issue with the aluminium chute. 
Due to the very rough, non-uniform nature and the variation in height of the scoured area in the lower chute, it was not possible to utilise the CNC methodology in this area. As an alternative, vertical aluminium templates (fitted together in a honeycomb effect), were used to generate the profile of this area. Vertical sections in two dimensions (parallel and perpendicular to the flow) were cut from aluminium using the two sets of survey data. The volume between templates was filled with sand and gravel, and the surface was capped with a $50 \mathrm{~mm}$ thick concrete layer. The maximum distance between templates was approximately $100 \mathrm{~mm}$, which is equivalent to 8 $\mathrm{m}$ in the prototype. This meant that smaller topographical features would not be captured by the model. In order to mitigate this issue, the templates near the ECS (main area of scour) were placed at a closer spacing in order to capture features up to $4 \mathrm{~m}$ in the model.

To simulate the smaller changes in topographical features, gravel was placed onto the concrete capping during model construction, which also provides a degree of turbulence and aeration for flow characteristics.

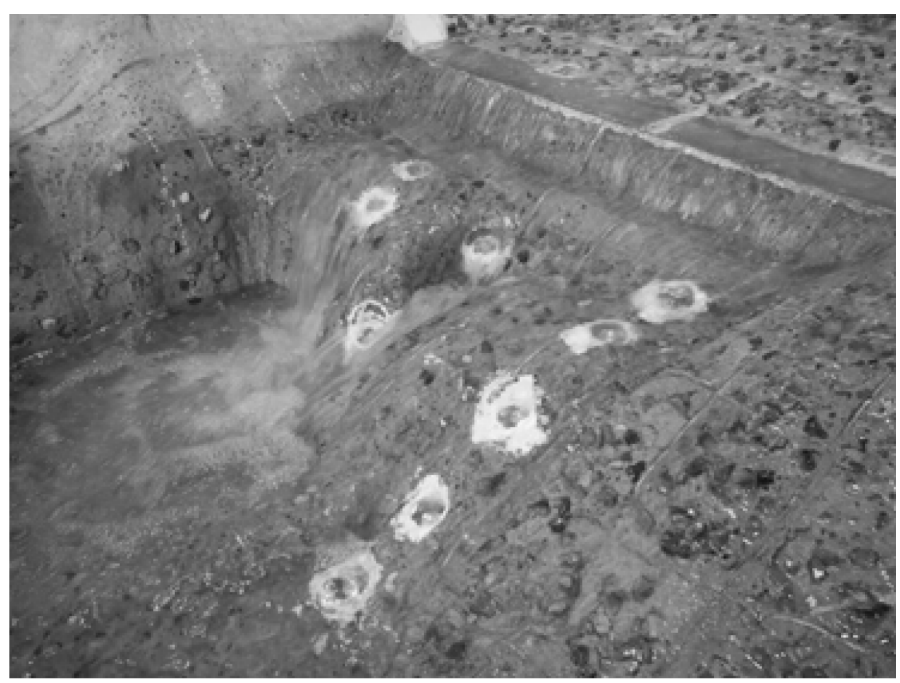

Figure 18. Lower chute post 2010/2011 arrangement

The observed scour pattern appears to be directly governed by the upstream flow conditions, including the turbulence intensity, flow velocity and depth of the turbulent flow at the ECS.

For the smooth chute conditions modelled in 2012, high velocities and low flow depths were observed. This led to long, uniform jet trajectories over the ECS. These jets impacted the plunge area at some distance downstream. Clearly these modelled conditions were not representative of actual phenomena. For very rough chute conditions on the prototype, turbulence, low velocities and high flow depths are expected. These would result in short and turbulent jets which impact much closer to the ECS. This behavior was observed on site at the dam during the 2010/11 and 2013 flood events.
It is clear that the surface roughness of the upper chute had a significant impact on the location and characteristics of the jet which formed the plunge pool downstream of the ECS. An accurate way to successfully model the surface roughness of the chute would be to observe the length of the jet in the spillway for known discharges, which could then be replicated in the model by changing the surface roughness. However, due to safety and operational constraints during flood events, this data is not available. The observation of scour patterns downstream of the ECS from the available photos and videos indicate that short and turbulent jet trajectories close to the ECS do occur during flood events.

In order to simulate the scoured rock surface, the surface profile was first machined in accordance with the post 2013 survey data. However, the finished surface lacked the necessary surface roughness. To simulate the roughness and turbulence in the model, several different sizes of gravel (between 5 and $20 \mathrm{~mm}$ ) were trialed on the model surface. It was found that gravel sizes less than $10 \mathrm{~mm}$ had little effect in increasing the surface roughness. Therefore, $10-20 \mathrm{~mm}$ in size gravel was adhered to the aluminium surface in order to introduce surface roughness in the model. The larger size gravel (20 $\mathrm{mm}$ ) was placed at a surface area coverage ratio of approximately $20 \%$. Gravel of the same size was also adhered to the upper chute sloped wall surfaces, to a height above the highest flow depths. Once placed, observations of the jet behavior showed the model was consistent with the onsite observations during the 2010/11 and 2013 flood events.

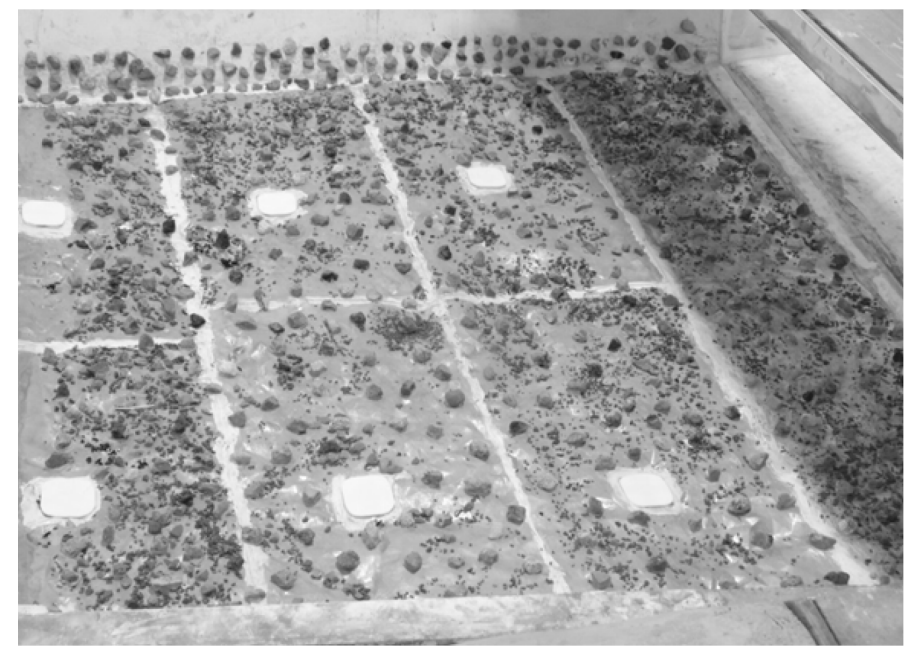

Figure 19. Upper chute arrangement with added gravel

However, there are drawbacks with this method. A $20 \mathrm{~mm}$ piece of gravel has an equivalent height of $1.6 \mathrm{~m}$ at full scale. This may compromise the form roughness to some extent. In the model it was observed that the negative impact of this gravel was mainly observed in small flood events (up to 1:30 AEP). As the modelling focused on flood events 
larger than this, this was considered acceptable for this project.

The instrumentation set-up for the Boondooma Dam physical model investigation consisted of the following:

- Electromagnetic flow meter in supply lines;

- Piezometer tappings for static pressures;

- Keller pressure transmitters, with flush diaphragms at selected points, for measurement of transient/dynamic pressures;

- 3D velocity measurements - Sontek Acoustic Doppler Velocimeter (ADV) for measurement of velocities;

- 2D velocity measurements - Nixon Streamflow 430 Velocity Meter, with Low and High speed velocity propeller probes;

- Vernier point gauges to measure water levels;

- Still and video cameras for recording flood event observations.

Three lines of measurement locations were selected. Twenty-three transducers and over forty other measuring points were located along the three lines. Figure 20 shows the location of all measurement points.

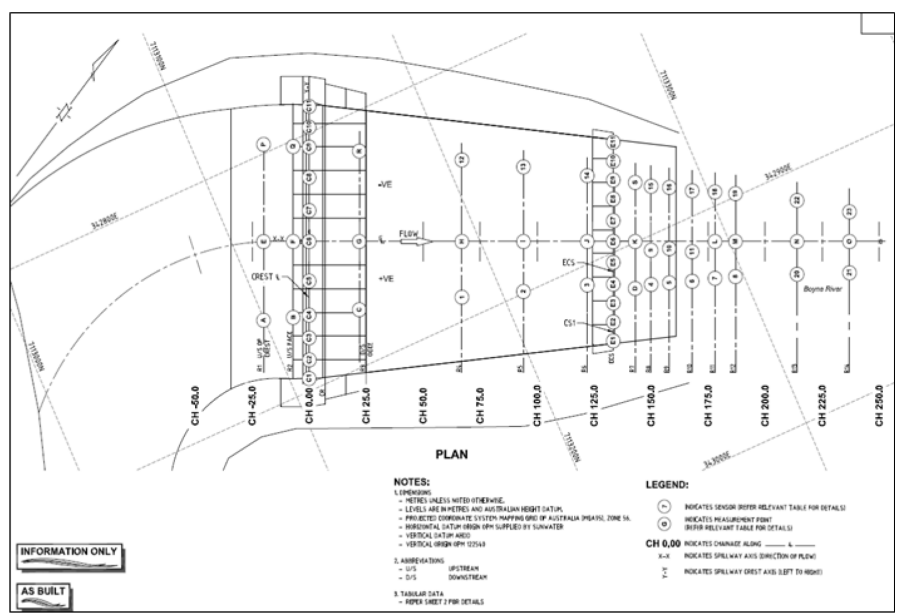

Figure 20. Pressure transducer arrangement at Boondooma Dam Model

Previous investigations and observations indicated that the most likely mechanism of failure would be via scour in the lower chute (plunge area) during floods. This is due to the direct impact of the jets on the area immediately downstream of the ECS. The progression of scour in the plunge pool could damage the ECS. Once the ECS is compromised, the scour can progress at the dykes and faults present in the upper chute as vehicles to advance quickly toward the spillway crest during future floods. Consequently, more measurement points and transducers are located in the plunge area compared to the upper chute.

Following sound calibration, the CSM has been used to estimate scour potential along each of the main lines of pressure recordings (Figure 20).
Figure 21 illustrates an example of long-term numerical scour predictions at the right hand side of the chutes, by adopting a flow duration curve that makes use of different AEP flood return periods.

First of all, it can be noticed that further significant scour would occur in the lower chute plunge pool, down to levels of about 210-215 $\mathrm{m}$ a.s.1., together with the most probable loss of the current ECS structure.

Also, significant scour is predicted through the upper chute, mostly starting along the scour vulnerable sub-vertical dykes. In fact, the dykes trigger scour in the surrounding more competent rock areas present along the upper chute. As such, in the longterm, potential loss of the upstream spillway crest cannot be excluded.

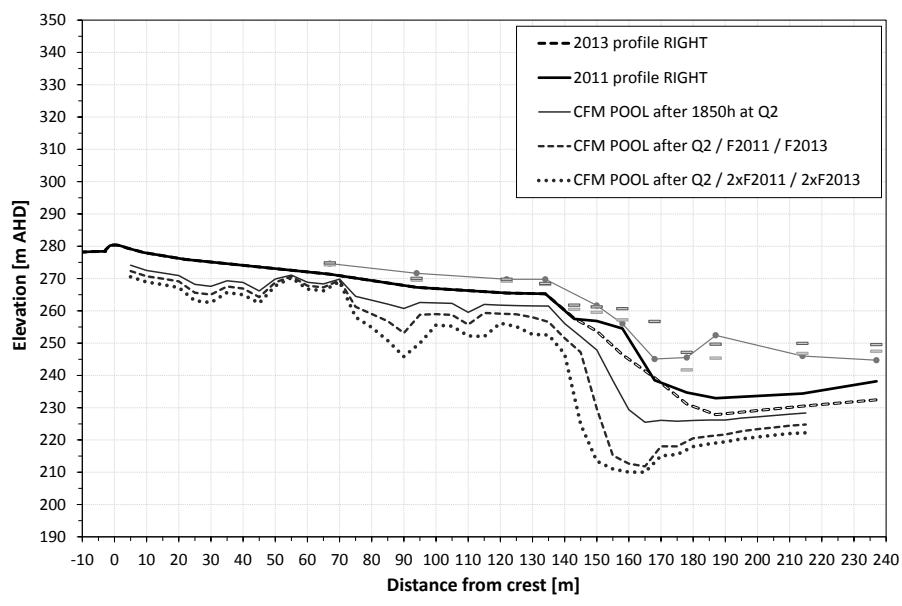

Figure 21. Computed scour potential at Boondooma Dam in the long-term (right hand side of chutes)

\section{CONCLUSIONS}

The paper uses a real situation of flood-induced scour to illustrate an advanced composite modelling methodology to evaluate the factors in hydraulics and energy dissipation that cause the scour of rock around dams and spillways.

The Paradise Dam experience is a notable example, similar to many others in different types of spillways, of how high-power flows are well able to scour rock - even rock which is apparently or seemingly hard and durable.

The methodology described herein illustrates two key components, in addition to a proper and full understanding of the local geology, namely (1) a wellscaled and instrumented physical hydraulic model and (2) a comprehensive, physics-based application of the data to the numerical analysis of pressure and pressure amplification to the breaking up and scour of rock. Composite application of both components allowed to soundly calibrate the numerical model and perform estimates of future scour progress for different discharge scenarios. 
Currently available modelling techniques, such as mobile bed arrangements, are not able to provide the required information for the CSM. Through the use of CNC machining and spillway roughness experimentation, the Boondooma Dam 3D physical hydraulic model has been able to effectively recreate the flow conditions of an unlined spillway chute to provide the required CSM inputs.

However, the adopted methodology clearly is not without its limitations. Flow characteristics in an unlined chute can be highly turbulent which can be difficult to measure accurately. Aeration in the model will always be less than at full scale (requiring manual adjustment when using the CSM).

Through the use of both physical hydraulic modelling and numerical modelling (CSM) SunWater is confident of being able to gain a good understanding of how and to what extent the scour may occur under future flood events. This will be a key input into selecting the long-term repair option for the spillway. The results will help to ensure the design and implementation of an option that is effective in mitigating future scour effects and securing the storage for the future.

\section{REFERENCES}

Bollaert, E.F.R. (2002). "Transient water pressures in joints and formation of rock scour due to high velocity jet impact." PhD Thesis $\mathrm{N}^{\circ} 2548$, Ecole Polytechnique Fédérale de Lausanne, Switzerland.

Bollaert, E.F.R. 2004. A comprehensive model to evaluate scour formation in plunge pools, Int. J. Hydropower \& Dams, 2004(1): pp 94-101.

Bollaert, E.F.R. 2010. "The Comprehensive Model: Theory and Feedback from Practice", 5th International Conference on Scour and Erosion, San Francisco.

Bollaert, E F R, \& Lesleighter, E J 2014. Spillway rock scour experiences and analysis - the Australian scene over the past four decades, Int. Symp. on Hydraulic Structures, Brisbane.

Bollaert, E F R, Stratford, C E, \& Lesleighter, E J (2015). Numerical modelling of rock scour, Case study of Wivenhoe Dam (Australia), In: Scour and Erosion, Proceedings Seventh International Conference on Scour and Erosion, Perth, Western Australia, 2-4 December 2014, (eds.) Cheng, L., Draper, S. and An, H., CRC Press/Balkema, p. 397-404.

Bowers, C E, \& Toso, J. 1988. Karnafuli project, model studies of spillway damage, ASCE Jl. of Hydraulic Division.

Bozorgmehr, P., McComber, S., Harrigan, D. \& Bollaert, E. 2015. Advancements Made in the 3D modelling of Unlined Spillway chutes and Applications of Comprehensive Scour Model, ANCOLD Conference Brisbane.

Lesleighter, E J, Andaroodi, P, \& Stratford, C E, 2012, Rock erosion experiences in the Wivenhoe Dam Spillway, $A N$ COLD conference.

Lesleighter, E J, Stratford, C E, \& Bollaert, E F R. 2013. Plunge pool rock scour experiences and analysis techniques, IAHR Congress, Chengdu, China.

McComber, S \& Bozorgmehr, P. 2015. "The Challenges Dam Owners Face When Considering Engineering Repairs in a Commercial Climate", ANCOLD National Conference 2015.
Whittaker et al. 1984. Communications of the laboratory of hydraulics, hydrology and glaciology, "Scour Related to Energy Dissipators for High Head Structures". 